\title{
SMART AND SUSTAINABLE TRANSPORT: SHORT REVIEW OF THE SPECIAL ISSUE
}

\author{
Kasthurirangan Gopalakrishnan ${ }^{1^{*}}$, Madhav V. Chitturi ${ }^{2^{*}}$, Olegas Prentkovskis ${ }^{3 * *}$ \\ ${ }^{1}$ Institute for Transportation, Iowa State University, United States \\ ${ }^{2}$ Traffic Operations and Safety (TOPS) Laboratory, Dept of Civil and Environmental Engineering, \\ University of Wisconsin-Madison, Madison, Wisconsin, United States \\ ${ }^{3}$ Dept of Transport Technological Equipment, Vilnius Gediminas Technical University, Lithuania \\ ${ }^{*}$ Guest Editor of the Special Issue on Smart and Sustainable Transport \\ of the research journal TRANSPORT \\ ${ }^{*}$ Editor-in-Chief of the research journal TRANSPORT
}

2 September 2015

Sustainable transport systems and infrastructure (roads, highways, bridges, airports, railways, waterways, etc.) strive to reduce the impact on the environment, the economy, and society in all aspects and throughout its life cycle from the conception to design, construction, maintenance, and operation. Sustainability is not a goal, but a process of continuous improvement according to the needs and the context, which can vary in time and space. A number of recent advances made in wireless smart sensor networks, nanotechnology, energy harvesting, high-performance computing, imaging and visualization, big data analytics, etc. has significant potential to accelerate the evolution of safe and smart Cyber Physical System (CPS) - enabled sustainable transport infrastructure and systems. This Editorial presents a short review of all 14 original papers and 1 review paper published in the current Special Issue on Smart and Sustainable Transport (SST), see Table.

Safe movement of visually impaired persons in the traffic network requires public services based on advanced Information and Communication Technologies (ICTs). Paper \#1 by Perisa et al. (current special issue: 247-252) analyzes the currently available information system of users when moving traffic network, and the current services bases on new ICTs. The analysis was carried out on a representative sample involving all interest groups of visually impaired people in the City of Zagreb (Croatia). New services based on two new ICTs, namely Near Field Communication (NFC) and RealTime Locating Systems (RTLS), were proposed to inform and facilitate communication with the visually impaired. The authors concluded that the proposed technologies successfully met their technical requirements and that more efficient usage of them has the potential to enrich the quality of lives of the blind and the visually impaired.

Autonomous driving systems have greater precision than human drivers in controlling a vehicle and can help address the demands of rapidly growing traffic volumes for safer and efficient use of roads by reducing the spacing between vehicles and thereby increase the road capacity. In Paper \#2, Godoy et al. (current special issue: 253-263) presents the results obtained during a driverless experiment (dubbed as the AUTOPIA program) conducted on a $100 \mathrm{~km}$ route around Madrid (Spain), including both urban and motorway environments. Very precise tracking results were obtained with the Cooperative Adaptive Cruise Control (CACC) with the distance error (between the leading and trailing vehicle) being kept to less than $1 \mathrm{~m}$. As part of future work, the authors recommended improvements on the localization system to allow longer GPS signal outages (such as while passing through a long tunnel, etc.).

Provision of real-time traveler information services is crucial both for travelers as well as for traffic managers. While Bluetooth is considered as one of the most economical options for estimating travel times, the process of data filtration and correction can be quite tedious. Paper \#3 by Mitsakis et al. (current special issue: 264-272) discusses a robust methodology for real-time estimation of travel times in dense urban networks using point-to-point Bluetooth detectors and applies it to a case study with 10 Bluetooth detectors installed at major intersections of Thessaloniki's Central Business District in Greece. The authors suggest that the proposed methodology can be extended to other similar technologies, such as automatic toll collection systems or Wi-Fi sensors.

Corresponding author: Kasthurirangan Gopalakrishnan

E-mail: rangan@iastate.edu 
Table. Contents of the Special Issue on Smart and Sustainable Transport

\begin{tabular}{|c|c|c|c|}
\hline & Title of the paper & Authors of the paper & Country \\
\hline Paper \#1 & $\begin{array}{l}\text { Adaptive technologies for the blind and visual } \\
\text { impaired persons in the traffic network }\end{array}$ & $\begin{array}{l}\text { Marko Periša }^{1}, \\
\text { Dragan Peraković } \\
\text { Juraj Vaculík }{ }^{3}\end{array}$ & $\begin{array}{l}1,2 \text { Croatia, } \\
{ }^{3} \text { Slovakia }\end{array}$ \\
\hline Paper \#2 & $\begin{array}{l}\text { A driverless vehicle demonstration on motorways } \\
\text { and in urban environments }\end{array}$ & $\begin{array}{l}\text { Jorge Godoy }{ }^{1} \text {, } \\
\text { Joshué Pérez }^{2} \text {, } \\
\text { Enrique Onieva }^{3} \text {, } \\
\text { Jorge Villagrá }{ }^{4}, \\
\text { Vicente Milanés } \\
\text { Rodolfo Haber }\end{array}$ & $\begin{array}{l}1,3,4,6 \text { Spain } \\
2,5 \text { France }\end{array}$ \\
\hline
\end{tabular}

Rodolfo Haber ${ }^{6}$

$\begin{array}{llll} & \text { A robust method for real time estimation of travel } & \text { Evangelos Mitsakis, } \\ \text { Paper \#3 } & \begin{array}{l}\text { Josep Maria Salanova Grau, } \\ \text { times for dense urban road networks using } \\ \text { point-to-point detectors }\end{array} & \begin{array}{l}\text { Evangelia Chrysohoou, } \\ \text { Georgia Aifadopoulou }\end{array} & \text { Greece }\end{array}$

\begin{tabular}{llll} 
& point-to-point detectors & Georgia Aifadopoulou & Hungary \\
\hline \multirow{2}{*}{ Paper \#4 } & $\begin{array}{l}\text { Route plan evaluation method for personalised } \\
\text { passenger information service }\end{array}$ & $\begin{array}{l}\text { Dávid Földes, } \\
\text { Csaba Csiszár }\end{array}$ & Ashu Shivkumar Kedia, \\
\hline \multirow{2}{*}{ Paper \#5 } & $\begin{array}{l}\text { Fuzzy logic approach in mode choice modelling } \\
\text { for education trips: a case study of Indian } \\
\text { metropolitan city }\end{array}$ & $\begin{array}{l}\text { Krishna Bhuneshwar Saw, } \\
\text { Bhimaji Krishnaji Katti }\end{array}$ & India \\
\hline
\end{tabular}

Piezoelectric force sensors for hexapod Tomas Luneckas,

Paper \#6 transportation platform Vytenis Gavelis,

Vytautas Valaitis,

Lithuania

Dainius Udris

\begin{tabular}{ll}
\hline Paper \#7 & $\begin{array}{l}\text { Setting the weights of sustainability criteria for } \\
\text { the appraisal of transport projects }\end{array}$ \\
\hline
\end{tabular}

Paper \#8 co-operative methodology to estimate car fuel
consumption by using smartphone sensors

Paola Carolina Bueno Cadena, José Manuel Vassallo Magro $\quad$ Spain

Vittorio Astarita,
Giuseppe Guido,
Domenico Mongelli, Italy
Vincenzo Pasquale Giofrè

How should the sustainability of the location of dry Samir Awad-Núñez, Nicoletta

Paper \#9 ports be measured? A proposed methodology using González-Cancelas,

$\begin{array}{ll}\begin{array}{l}\text { Bayesian networks and multi-criteria } \\ \text { decision analysis }\end{array} & \text { Francisco Soler-Flores, } \\ & \text { Alberto Camarero-Orive }\end{array}$

Erik Wilhelm ${ }^{1}$,

Joshua Siegel ${ }^{2}$,

Simon Mayer ${ }^{3}$ ' 1 Singapore,

Leyna Sadamori ${ }^{4}$ 2,7 United States,

Chi-Kin Chau',

Sanjay Sarma ${ }^{7}$

5, ${ }^{3}$ United Arab Emirates

Paper \#10 $\begin{aligned} & \text { CloudThink: a scalable secure platform for } \\ & \text { mirroring transportation systems in the cloud }\end{aligned}$

Applying sustainability theory to transport

Paper \#11 infrastructure assessment using a multiplicative AHP decision support model

Paper \#12 $\begin{aligned} & \text { Sustainability effects of next-generation intersection } \\ & \text { control for autonomous vehicles }\end{aligned}$

\section{Marie Ridley Pryn,}

Yannick Cornet,

Kim Bang Salling

Zhixia (Richard) Li,

Madhav V. Chitturi,

Lang Yu,

Andrea R. Bill,

David A. Noyce

Guodong Yin,

Jianghu Li

XianJian Jin,

Chentong Bian,

Nan Chen

$\begin{array}{ll}\text { Srećko Krile }^{1}, & { }^{1,2} \text { Croatia, } \\ \text { Marina Krile }^{2}, & { }^{3} \text { Czech Republic } \\ \text { Petr Průša } & \end{array}$

Paper \#14 Non-linear mini-max problem of multi-stop flight routes

Applicability of ICT solutions in passenger

Paper \#15 transport - case studies from different European backgrounds
Monika Bąk,

Przemysław Borkowski
Denmark

United States

China

${ }^{1,2}$ Croatia,
${ }^{3}$ Czech Republic

Poland 
Paper \#4 by Földes and Csiszár (current special issue: 273-285) focusses on improving the customer satisfaction and perception of public transportation system quality by developing route plan evaluation method based on personalized user settings. By considering both the precise physical aspects of the infrastructure (such as detailed properties of walking paths, passenger facilities and vehicles) and the users' detailed personal preferences, the novel algorithm developed by the authors determines 'ideal routes' that are closer to reality than those of existing route planner applications. Areas of future research identified by the authors include multicriteria survey of passenger demands and expectations for journey planner applications, analysis of stated and revealed personalized preferences, etc.

Rural-urban migration, especially in developing countries has been placing enormous pressure on urban infrastructure, especially the transportation system resulting in ever-increasing congestion and consequent emissions. Essential to developing sustainable transportation approaches for urban areas is having an understanding of mode choice and what prompts users to make a modal shift. The conventional logit modelling approach cannot accommodate uncertainty in the choice decisions. Kedia et al. (current special issue: 286-293) present a novel fuzzy logic approach to mode choice modeling for education trips and demonstrate its use in an Indian metropolitan city.

Wheeled or tracked robots are not suitable for payload transportation that require rough terrain traversability or very stable and careful movements. For this reason, walking robots, despite their slower speed, have been attracting recent attention as transportation platforms that can overcome the environment. However, stable motion of walking robots over the irregular surface requires accurate supervision of leg placement and the development of force sensing system on each foot of the robot for equal force distribution between legs. Different types of sensors could be used in the development of robot's force sensing system such as barometers, pressure sensors, etc. Paper \# 6 by Luneckas et al. (current special issue: 294-297) successfully investigates the improvement of a hexapod robot's feet by upgrading them with piezoelectric sensors. As part of future research, the authors intend to build unique barometer sensors for the hexapod robot and monitor the force distribution over a longer period.

Paper \#7 by Bueno Cadena and Vassallo Magro (current special issue: 298-306) presents a novel methodology to set the weights of the sustainability criteria used in the Multi-Criteria Decision Analysis (MCDA) of transport projects in order to reduce the subjectivity and imprecision. Their proposed approach recommends eliciting weights based on both expert preferences as well as the importance that the sustainability criteria have in the geographical and social context where the transport project is developed. The authors successfully applied their methodology to a real case study to quantify sustainable practices associated with the design and construction of a new roadway in Spain.
Climate change is intimately related to Greenhouse Gas Emissions (GHG). Transportation sector is the second largest source of GHG and consequently the quest to use novel approaches to minimize emissions from vehicles. The advent of vehicle-to-vehicle and vehicleto-infrastructure communications provides an opportunity to potentially modify driver behavior resulting in reduced fuel consumption and resultant emissions. Paper \#8 by Astarita et al. (current special issue: $307-311$ ) presents a co-operative methodology to estimate car fuel consumption by using smartphone sensors to detect vehicle kinematics. The preliminary results reported by the authors demonstrate that the proposed system provides reliable estimates of fuel consumption.

Implementation of dry ports can potentially mitigate the adverse impacts of increase in activity at seaports as well as act as a link between road and railroad networks and thus strengthen intermodal solutions. However, location of dry ports requires thorough analysis of the whole logistics supply chain with aim of transferring largest volume of goods from road to more energy-efficient transportation mode with minimal environmental impact. Paper \# 9 by Awad-Núñez et al. (current special issue: 312-319) investigates the variables influencing the sustainability of a dry port location and presents a methodology for assessing the sustainability of dry port locations through the use of MCDA and Bayesian Networks (BNs).

Vehicle data can be leveraged to improve vehicle performance, reliability, efficiency, safety, operational costs and user experience. Paper \#10 by Wilhelm et al. (current special issue: 320-329) presents CloudThink, a scalable secure platform for mirroring transportation systems in the Cloud. The hallmark of CloudThink is the balance between flexibility to host many applications and the ability to securely store user data. The platform consists of low-cost, open-source hardware for capturing vehicle data and moving securely to a server, a webbased Application Programming Interface (API) for provision of 3rd party services and dashboard for access control and service distribution. CloudThink can enable a whole host of applications in the transportation domain including energy, environmental and policy. Three third-party applications using CloudThink data are discussed: remote vehicle actuation, vehicle state of health monitoring, and fleet eco-driving use.

In Paper \#11, Pryn et al. (current special issue: 330-341) propose the SUSTAIN Decision Support System (DSS), a conceptualized approach to sustainability based on the nested model, as an alternative approach to traditional sustainable transportation assessment based on the three dimensions of economy, society and the environment. Based on the basic notions of sustainability presented by the historic Brundtland Commission report and the use of MCDA and a multiplicative version of the Analytical Hierarchy Process (AHP), the proposed approach provides a sound rationale for prioritizing longer-term ecological integrity over shorterterm economic concerns. As a case study, the authors successfully applied and demonstrated their proposed 
approach in the planning and decision-making process related to a new construction across the Roskilde Fjord in Frederikssund, Denmark.

Paper \#12 by Li et al. (current special issue: $342-$ 352) presents ACUTA, a next-generation, enhanced reservation-based algorithm for control of autonomous vehicles at intersections. VISSIM, a microscopic traffic simulation platform was used to model ACUTA. The objective was to evaluate the sustainability impacts of ACUTA and compare it with traditional intersection control such as all way stop and signal control. MOVES, a state-of-the-art tool developed by the Unites States Environmental Protection Agency (EPA) was used for estimating emissions and energy consumption of vehicles. Results show that ACUTA has great potential in reducing pollutant emissions and energy consumption at intersections. Authors conjecture that the sustainability benefits could be maximized by extending ACUTA to a corridor as opposed to a single intersection.

Paper \#13 by Yin et al. (current special issue: $353-$ $360)$ integrated motion planning and model-predictivecontrol (MPC) based control system for autonomous electric vehicles. The proposed system is evaluated under two scenarios with a high-fidelity full vehicle model from CarSim using a seven degrees-of-freedom vehicle model. The two scenarios are lane changing maneuver and right angle turn maneuver. The simulation results demonstrate that the integrated planner and controller can meet the requirements of autonomous driving.

Every industry is in the quest for increased operational efficiency, productivity, safety, customer service and ultimately profitability. In air transport industry, multi-stop routes could result in significant fuel savings and better capacity utilization. Paper \#14 by Krile et al. (current special issue: 361-371) developed an efficient heuristic algorithm for optimal transportation on multistop routes. The goal is to minimize idle capacity, expenses and maximize revenue by formulating the problem as a minimum cost multi-commodity flow problem rather than a non-linear convex optimization problem. The authors demonstrate the viability and computational efficiency of this approach through several test examples.

In Paper \#15 Bąk and Borkowski (current special issue: $372-381$ ) studied the acceptability of ICT solutions and barriers to their implementation through focus groups and interviews. Five case studies were conducted across the European Union covering a wide range of geographic, social and economic factors. The five studies are: smartphone applications (apps) for improving accessibility for disabled people in London (United Kingdom), ITS solutions for Barcelona's (Spain) local bus network, bike-sharing in Vienna and surrounding region (Austria), a grass-root cooperative smartphonebased car-sharing in Austria, and interurban public transport in Warmian-Masurian Voivodeship (WarmiaMasuria Province) of Poland. The main findings are that users have similar positive attitudes towards ICT regardless of social, economic and cultural backgrounds. Users expect ICTs to be delivered for free or economically. Most useful ICTs appear to be those aimed at pricing and ticket integration. 